\title{
Genetic and environmental influences on cortical mean diffusivity
}

Authors: Jeremy A. Elman PhD ${ }^{a, b}$, Matthew S. Panizzon PhD ${ }^{a, b}$, Donald J. Hagler, Jr., $\mathrm{PhD}^{c}$, Christine Fennema-Notestine PhD ${ }^{a, c}$, Lisa T. Eyler PhD ${ }^{a, d}$, Nathan A. Gillespie PhD ${ }^{\mathrm{e}}$, Michael C. Neale $\mathrm{PhD}^{\mathrm{e}}$, Michael J. Lyons $\mathrm{PhD}^{f}$, Carol E. Franz PhD' ${ }^{\mathrm{a}, \mathrm{b}}$, Linda K. McEvoy, $\mathrm{PhD}^{\mathrm{c}}$, Anders M. Dale, $\mathrm{PhD}^{\mathrm{c}, \mathrm{g}}$, William S. Kremen $\mathrm{PhD}^{\mathrm{a}, \mathrm{b}, \mathrm{d}}$

b

d San Diego VA Health Care System, San Diego, CA 92161, USA

e Virginia Institute for Psychiatric and Behavior Genetics, Virginia Commonwealth University, VA, USA

f Department of Psychological and Brain Sciences, Boston University, Boston, MA, USA

g Department of Neurosciences, University of California San Diego, CA, USA

\section{Correspondence:}

Jeremy A. Elman

Department of Psychiatry

University of California, San Diego

9500 Gilman Dr. (MC0738)

La Jolla, CA 92093

Phone: (858) 534-6842

E-mail: jaelman@ucsd.edu 


\begin{abstract}
Magnetic resonance imaging (MRI) has become an important tool in the early detection of agerelated and neuropathological brain changes. Recent studies suggest that changes in mean diffusivity (MD) of cortical gray matter derived from diffusion MRI scans may be useful in detecting early effects of Alzheimer's disease (AD), and that these changes may be detected earlier than alterations associated with standard structural MRI measures such as cortical thickness. Thus, due to its potential clinical relevance, we examined the genetic and environmental influences on cortical MD in middle-aged men to provide support for the biological relevance of this measure and to guide future gene association studies. It is not clear whether individual differences in cortical MD reflect neuroanatomical variability similarly detected by other MRI measures, or whether unique features are captured. For instance, variability in cortical MD may reflect morphological variability more commonly measured by cortical thickness. Differences among individuals in cortical MD may also arise from breakdowns in myelinated fibers running through the cortical mantle. Thus, we investigated whether genetic influences on variation in cortical MD are the same or different from those influencing cortical thickness and MD of white matter (WM) subjacent to the cortical ribbon. Univariate twin analyses indicated that cortical MD is heritable in the majority of brain regions; the average of regional heritability estimates ranged from 0.38 in the cingulate cortex to 0.66 in the occipital cortex, consistent with the heritability of other MRI measures of the brain. Trivariate analyses found that, while there was some shared genetic variance between cortical MD and each of the other two measures, this overlap was not complete (i.e., the correlation was statistically different from 1). A significant amount of distinct genetic variance influences inter-individual variability in cortical MD; therefore, this measure could be useful for further investigation in studies of neurodegenerative diseases and gene association studies.
\end{abstract}

Keywords: Mean diffusivity, magnetic resonance imaging, cortex, twins, heritability 


\section{Introduction}

Magnetic resonance imaging (MRI) measures of brain structure and function provide in vivo biomarkers to assess alterations associated with normal aging, disease onset and progression, as well as treatment efficacy. A substantial portion of the variance in MRI measures is under genetic control (Blokland et al., 2012; Eyler et al., 2011b; Kremen et al., 2010; Panizzon et al., 2009; Panizzon et al., 2012; Rimol et al., 2010). However, different MRI sequences and outcome metrics may provide unique information (Panizzon et al., 2009) and, thus, independent contributions to understanding disease state, risk, or progression. Recent studies have supported the strong potential for diffusion MRI (dMRI) to provide a sensitive marker of early disease onset or risk that may be independent from commonly used morphological metrics within the gray matter, such as cortical thickness. Metrics from dMRI provide an index of microstructural properties of the brain by measuring the degree and direction of movement of water molecules (Beaulieu, 2002), and strong relationships have been found between age and these microstructural properties of both white and gray matter (Abe et al., 2008; Benedetti et al., 2006; Salat et al., 2005).

Recent studies have found that the dMRI metric of mean diffusivity (MD), the average diffusion across all directions, may be a sensitive marker of neuronal damage in both cell bodies and axonal fibers. Changes in MD may result from a breakdown of cytoarchitectural barriers such as cell membranes that restrict water diffusion, or from a shift in the concentration of water between intra- and extracellular spaces (Neil et al., 2002; Sundgren et al., 2004; Van Camp et al., 2012). Altered MD within white and gray matter has been found in various diseases, including multiple sclerosis (Cercignani et al., 2001), Huntington's disease (Van Camp et al., 2012), Creutzfeld-Jakob disease (CJD; Demaerel et al., 1999; Ukisu et al., 2005; Zerr et al., 2009), and mild cognitive impairment (MCl; Fellgiebel et al., 2004; Kantarci et al., 2001; Ray et al., 2006). Such altered microstructure may presage future changes in cognition or 
morphological measures of the brain that are commonly used to assess disease progression. Indeed, baseline MD predicts later decline in episodic memory (Müller et al., 2005) and progression from MCI to Alzheimer's disease (AD; Douaud et al., 2013; Fellgiebel et al., 2006; Kantarci et al., 2005; Müller et al., 2005; Scola et al., 2010). Furthermore, MD alterations have been found in presymptomatic carriers of familial AD gene mutations (Fortea et al., 2010; Ryan et al., 2013) and in cognitively normal adults with evidence of amyloid deposition (Molinuevo et al., 2014). Thus microstructural changes may provide a useful marker for risk of future neurodegeneration, and in many of these studies, gray matter MD provided higher classification accuracy than did gray matter volume.

While most of the studies assessing the utility of dMRI-derived measures have focused on white matter or subcortical gray matter structures such as the hippocampus, cortical measures of dMRI have great potential to provide a unique marker of integrity. In contrast to WM, where motion tends to be restricted along the direction of axonal bundles, MD may be the most relevant dMRI measure in the cortex because water diffusion in gray matter (GM) is presumably isotropic (at least at conventional dMRI resolution). Altered cortical MD has been studied in the context of $A D$, as $A D$ pathophysiology is highly associated with degeneration in cortical GM (Braak and Braak, 1991, 1996, 1998; Jack et al., 2013; Jack et al., 2008). Adults with either MCl or high genetic risk for $A D$ show increased cortical MD compared to cognitiviely normal adults (Fellgiebel et al., 2004; Jacobs et al., 2013; Ray et al., 2006; Scola et al., 2010; Weston et al., 2015). Measures of cortical MD are also able to successfully discriminate the subtler differences between AD and dementia with Lewy bodies (Kantarci et al., 2010), and cortical MD begins to increase more generally in middle age (Ni et al., 2010). While the dMRI measures of white matter have been found to be heritable (Chiang et al., 2009; Kochunov et al., 2010), the genetic and environmental influences on cortical MD have yet to be elucidated.

Alterations in dMRI-derived measures within WM related to age, injury, or disease are often thought to reflect myelin damage and/or axonal injury, with supporting evidence coming from 
histological and lesion studies (Beaulieu, 2002; Beaulieu et al., 1996; Concha et al., 2010; Fraidakis et al., 1998; Pierpaoli et al., 2001; Song et al., 2003; Song et al., 2002; Song et al., 2004; Sun et al., 2005). However, the neuroanatomical underpinnings of cortical MD remain unclear. Differences in MD have been proposed to reflect "expansion of the extracellular space corresponding to a decrease in membrane density due to cell degeneration" (Douaud et al., 2009). In this case, cortical MD may be directly related to cortical thickness in that accumulating microstructural damage could eventually manifest as macrostructural changes (i.e., reduced thickness). It is also possible that changes in cortical MD partially reflect contributions of myelinated fibers coursing through the cortical mantle. For instance, AD has been proposed as a response precipitated by age-related breakdowns in myelination (Bartzokis, 2011). The patterns of neurofibrillary changes related to $A D$ appear in late myelinating cortical regions (Braak and Braak, 1996, 1998; Braak et al., 2000), and intracortical myelin may be particularly susceptible to such degeneration (Bartzokis, 2011; Bartzokis et al., 2007). Prior studies have found that changes in WM signal intensity subjacent to the cortex underlie age-related declines in white/gray contrast (Salat et al., 2009), and that MRI signal within cortical voxels may be partially influenced by intracortical myelin (Eickhoff et al., 2005; Paus, 2005). Therefore, factors that influence cortical MD may be similar to those influencing measures of MD sampled in proximal locations of WM if changes in myelination underlie variation in both measures.

Prior studies have found substantial genetic influences on most MRI measures of brain structure, including cortical thickness (Kremen et al., 2010; Panizzon et al., 2009; Rimol et al., 2010) and surface area (Eyler et al., 2011b; Winkler et al., 2012). Diffusion properties of the brain, particularly in WM, also appear to be heritable (Chiang et al., 2009; Kochunov et al., 2010). Elucidating the heritability of cortical MD will provide support for its biological relevance and to determine its usefulness in future gene association studies. It is also possible to calculate genetic correlations, which is the amount of shared genetic influences between structures or imaging modalities. Genetic correlations between structures have been used to provide insight 
into the structural organization of the brain (Chen et al., 2013; Chen et al., 2012; Eyler et al., 2011a). Examining the genetic correlation of cortical MD with other imaging phenotypes can determine whether this measure constitutes a unique imaging phenotype. For example, cortical thickness and surface area are both heritable but have little genetic overlap (Panizzon et al., 2009; Winkler et al., 2010), indicating that these measures capture unique neuroanatomical information. Such information can serve to sharpen the imaging phenotypes used in genetic studies and, in the case of cortical MD, determine whether it is worthwhile to collect dMRI in addition to more commonly acquired measures of brain structure such as cortical thickness.

In the present study, we employed classical twin methods in a large sample of middle-aged twins to determine genetic and environmental contributions to cortical MD. The twin model also allows us to investigate environmental and genetic correlations between cortical MD and both cortical thickness, a putative measure of cellular macrostructure, and WM MD subjacent to the cortical mantle, a microstructural measure of myelinated axons. The genetic correlation indicates the degree to which there are shared or distinct genetic influences on individual variations in these imaging measures.

\section{Methods}

\subsection{Participants}

Participants were from wave 2 of the Vietnam Era Twin Study of Aging (VETSA) project (Kremen et al., 2013; Kremen et al., 2006). VETSA participants comprise a national, community-dwelling sample of male-male twins who are similar to American men in their age range with respect to health and lifestyle characteristics based on Center for Disease Control and Prevention data (Schoeneborn and Heyman, 2009). All served in the military service sometime between 1965 and 1975, but nearly 80\% reported no combat exposure.

The VETSA2 MRI component included 447 subjects using standard MRI exclusion criteria (e.g., no metal in the body). Of these, diffusion data from 47 subjects and structural MRI data from 41 subjects was either missing or excluded due to poor quality (e.g., movement, artifacts, 
etc.). Subjects were included in the study if they had useable data from at least one modality. This resulted in a final sample of 420 subjects, 364 of whom had both structural and diffusion data available. The sample had a mean age of 61.8 years (range $56-66$; $S D=2.6$ ), was primarily Caucasian $(91.4 \%)$ and had a mean education of $13.8(S D=2.1)$ years. The twin models were based on 96 monozygotic (MZ) pairs, 67 dizygotic (DZ) pairs and 94 unpaired individuals (i.e., participants whose co-twin either was not scanned or whose data was not useable). Members of each twin pair were scanned on the same magnet.

The study was approved by the Institutional Review Boards at the University of California, San Diego (UCSD), Boston University (BU), and the Massachusetts General Hospital (MGH).

\subsection{MRI Acquisition}

Images were acquired at two sites, UCSD $(n=256)$ and MGH $(n=164)$. At UCSD, images were acquired with a GE 3T Discovery 750× scanner (GE Healthcare, Waukesha, WI, USA) with an eight-channel phased array head coil. The imaging protocol included a sagittal 3D fast spoiled gradient echo (FSPGR) $\mathrm{T}_{1}$-weighted volume optimized for maximum gray/WM contrast [TE $=3.164 \mathrm{msec}, \mathrm{TR}=8.084 \mathrm{msec}, \mathrm{TI}=600 \mathrm{msec}$, flip angle $=8^{\circ}$, pixel bandwidth $=244.141$, matrix $=256 \times 192$, in-plane resolution $=1 \times 1 \mathrm{~mm}$, slice thickness $=1.2 \mathrm{~mm}$, slices $=172]$, and a diffusion-weighted scan with 51 diffusion directions [b value $=1000 \mathrm{~s} / \mathrm{mm}^{2}$, integrated with a pair of $b=0$ images with opposite phase-encode polarity, $\mathrm{TR}=9700 \mathrm{msec}, \mathrm{TE}=80-84 \mathrm{msec}$, pixel bandwidth $=3906.25$, matrix $=96 \times 96$, in-plane resolution $=2.5 \times 2.5 \mathrm{~mm}$, slice thickness $=2.5$ $\mathrm{mm}$, slices $=51]$.

At $\mathrm{MGH}$, images were acquired with a Siemens Tim Trio, (Siemens USA, Washington, D.C.) with a 32 channel head coil. The imaging protocol included a 3D magnetization-prepared rapid gradient-echo (MPRAGE) $T_{1}$-weighted volume optimized for maximum gray/WM contrast $[\mathrm{TE}=$ $4.33 \mathrm{msec}, \mathrm{TR}=2170 \mathrm{msec}, \mathrm{TI}=1100 \mathrm{msec}$, flip angle $=7^{\circ}$, pixel bandwidth $=140$, matrix $=$ $256 \times 256$, in-plane resolution $=1 \times 1 \mathrm{~mm}$, slice thickness $=1.2 \mathrm{~mm}$, slices $=160]$, and diffusion- 
weighted scans including two separate $b=0$ images with opposite phase-encode polarity, followed by two scans with 30 diffusion directions [b value $=1000 \mathrm{~s} / \mathrm{mm}^{2}$ (and one $b=0$ image), $\mathrm{TR}=9500 \mathrm{msec}, \mathrm{TE}=94 \mathrm{msec}$, pixel bandwidth $=1371$, matrix $=96 \times 96$, in-plane resolution $=$ $2.5 \times 2.5 \mathrm{~mm}$, slice thickness $=2.5 \mathrm{~mm}$, slices $=64]$.

\subsection{MRI Processing}

Structural MR images were processed as described previously (Kremen et al., 2010; McEvoy et al., 2015) using the FreeSurfer software package (Dale et al., 1999; Fischl and Dale, 2000; Fischl et al., 1999; Fischl et al., 2004). Briefly, this involves correction of distortion due to gradient nonlinearity (Jovicich et al., 2006), image intensity normalization, rigid registration into standard orientation with $1 \mathrm{~mm}$ isotropic voxel size, and removal of non-brain tissue. Boundaries between GM, WM, and cerebral spinal fluid (CSF) were defined and the cortical surface was then divided into 66 distinct regions (33 per hemisphere) according to the Desikan-Killiany atlas (Desikan et al., 2006; Fischl et al., 2004). Surface area and mean cortical thickness was calculated for each ROI. All raw and processed images were visually inspected for quality.

Briefly, dMRI images were processed as follows. A robust and accurate procedure for reducing spatial and intensity distortions in EPI images caused by $\mathrm{B}_{0}$ field was applied (Holland, et al. 2010) that relies on the reversing gradient method (Chang and Fitzpatrick, 1992, Morgan et al., 2004). Pairs of $b=0$ (i.e. non-diffusion weighted) images with opposite phase encoding polarities (and thus opposite spatial and intensity distortion patterns) were aligned using a fast, nonlinear registration procedure. The displacement field volume was adjusted (i.e. translation and rotation) for estimated head motion and then used to unwarp distortions in each frame (i.e. diffusion-weighted volume). Eddy current distortions were corrected with a nonlinear estimation procedure that used the diffusion gradient orientations and amplitudes to predict the pattern of distortions across the entire set of diffusion weighted volumes (Zhuang et al., 2006). Corrections were restricted to translation and scaling along the phase-encode direction, avoiding spurious 
head rotations introduced by affine registration. Gradient nonlinearity distortions were corrected for each frame (Jovicich et al., 2006). Head motion was corrected by registering each frame to a corresponding image synthesized from a tensor fit, thus accounting for variation in image contrast across diffusion orientations (Hagler et al., 2009). The diffusion gradient matrix was then adjusted for head rotation (Hagler et al., 2009, Leemans and Jones, 2009). For both motion correction and eddy current distortion correction, robust diffusion tensor estimation was used to exclude the contribution of dark slices, which are caused by abrupt, severe head motion. As part of motion correction, such outlier values were replaced -- an entire slice at a time for a given diffusion direction -- with values synthesized from the robust tensor fit. $\mathrm{T}_{2^{-}}$ weighted $b=0$ images were registered to $T_{1}$-weighted structural images using mutual information (Wells et al., 1996) after coarse pre-alignment via within-modality registration to atlas brains. This provides a robust and accurate registration, and registrations were reviewed manually for quality. Diffusion-weighted images were resampled into a standard orientation with $2 \mathrm{~mm}$ isotropic resolution; the number of resampling steps was reduced by combining this with the motion correction. Cubic interpolation was used for all resampling steps. Conventional diffusion tensor imaging (DTI) methods were used to model the diffusion tensor as an ellipsoid where eigenvalues $\lambda_{1}, \lambda_{2}$, and $\lambda_{3}$ define the three primary axes (Basser et al., 1994; Le Bihan et al., 2001; Pierpaoli et al., 1996), and mean diffusivity (MD) was calculated as the average diffusion in all directions. Raw and processed images were visually inspected to exclude data with severe scanner artifacts or excessive head motion.

At each vertex, seven samples were taken in $0.2 \mathrm{~mm}$ increments along the vector normal to the gray/white boundary surface, from $0.8 \mathrm{~mm}$ to $2 \mathrm{~mm}$ in both directions (e.g., outwards into the cortical mantle or inwards into pericortical WM; see Supplemental Figure S1 for graphical depiction). Multiple samples were taken because these vectors may be oblique to the image matrix, and can thus pass through multiple voxels with varying properties. Samples were not taken at the boundaries of the cortical ribbon due to the potential for small errors in 
coregistration which may result in edges partially overlapping with CSF or WM. In order to minimize the effects of partial voluming and regional variations in cortical thickness, we calculated weighted averages of MD based on the proportion of white or gray matter in each voxel. White and gray matter voxels were labeled using the cortical surfaces generated by FreeSurfer in processed $T_{1}$ image resolution ( $1 \mathrm{~mm}$ isotropic). These masks were resampled into the resolution of the pre-processed $\mathrm{dMRI}$ image ( $2 \mathrm{~mm}$ isotropic) using cubic interpolation. Thus, every voxel in the dMRI image was given a corresponding volume fraction ranging from 0 to 1 representing the proportion of each tissue type of interest contained in the voxel. Volume fraction maps were created for both white and gray matter to be used in calculating WM MD and cortical MD, respectively. The 7 samples along the normal vector at each surface vertex were averaged using weights determined by the volume fraction map of each tissue type. The weighting factor given to each voxel was calculated using Tukey's bisquare weight function (Beaton and Tukey, 1974):

$$
w(x)=\left\{\begin{aligned}
\left(1-\left(\frac{1-v}{t}\right)^{2}\right)^{2}, & v>t \\
0, & v \leq t
\end{aligned}\right.
$$

where $v$ is the volume fraction and $t$ is a tunable scaling factor, here set to 0.5 . In practical terms, this will set any voxel with a volume fraction less than 0.5 to 0 , and any voxel with a volume fraction above 0.5 to a weight ranging between 0 and 1 . This weighting function was used to exclude or downweight the contribution of voxels with a low proportion of the tissue of interest (i.e., GM or WM). In addition to its use in robust estimation, previous uses of the Tukey bisquare weight function have included edge-finding in noisy images (Black et al., 1998), image registration (Hsu et al., 2001), and image segmentation (Samaille et al., 2012). Average MD was calculated for all 66 ROls in the Desikan-Killiany atlas (Desikan et al., 2006). Based on our previous findings of no genetic differences in cortical thickness or surface area in homologous left and right hemisphere ROIs (Kremen et al., 2010; Eyler et al., 2014), we averaged left and 
right hemispheres for a total of 33 bilateral ROI values. Genetic correlations of cortical MD between hemispheres was also examined to further support bilateral averaging (see

\section{Supplemental Results).}

\subsection{Statistical Analysis}

To determine the relative influence of genetic and environmental factors on MD, we fit univariate biometrical models (also referred to as ACE models) to the estimates of cortical MD. In the classical twin design, the variance of a phenotype is decomposed into additive genetic (A) influences, common or shared environmental (C) influences (i.e., environmental factors that make members of a twin pair similar to one another), and unique environmental $(E)$ influences (i.e., environmental factors that make members of a twin pair different from one another, including measurement error) (Eaves et al., 1978; Neale and Cardon, 1992). Additive genetic influences are assumed to correlate perfectly (1.0) between MZ twins because they are generally genetically identical. DZ twins, on the other hand, share on average $50 \%$ of their segregating DNA, and are therefore assumed to correlate .50 for additive genetic influences. The shared environment, by definition, correlates 1.0 between both members of a twin pair, regardless of their zygosity, and because non-shared environments $(E)$ are by definition uncorrelated, E must also reflect measurement error. The proportion of the overall variance in a phenotype that is attributable to additive genetic influences is the heritability. This modeling assumes mean and variance homogeneity both within twin pairs and across zygosity. Prior to analysis, mean and variance homogeneity was satisfied at each region. The full ACE model was used for both univariate and multivariate analyses.

To examine the genetic and environmental associations between cortical MD, WM MD and cortical thickness, we also performed a trivariate ACE model. We used full information maximum likelihood (FIML) to allow inclusion of subjects missing structural MRI or dMRI data. When extended to multivariate scenarios, the twin design can further decompose the 
covariance between phenotypes into genetic and environmental components. Doing so allows for the estimation of genetic and environmental correlations between variables (representing the degree of shared genetic and shared environmental variance), thereby allowing one to determine if the latent genetic and environmental influences of multiple phenotypes overlap in any way. To confirm our expectation of no differences in the genetic influences underlying homologous left and right hemisphere ROls, we ran a bivariate ACE model to test phenotypic and genetic correlations between cortical MD in ROls from each hemisphere. Correlations were determined to be significantly different from 0 or 1 by examining $95 \%$ confidence intervals (Cls). All analyses, both univariate and multivariate, were performed using the raw data application of the maximum-likelihood based structural equation modeling software OpenMx (Boker et al., 2011).

Age and site effects were examined using a linear mixed model with family ID (given to both individuals in each twin pair) as a random effect to account for correlations between co-twins. Measures were adjusted prior to the twin analyses by regressing out the effects of age and site (scanner), and then standardized with a z-transform.

\section{Results}

Values of cortical MD ranged from $0.89\left(10^{-3} \mathrm{~mm}^{2} / \mathrm{s}\right)$ in the inferior temporal gyrus to 1.34 $\left(10^{-3} \mathrm{~mm}^{2} / \mathrm{s}\right)$ in the postcentral gyrus. When averaging ROls within lobes, the cortical MD was lowest in the cingulate cortex (mean=0.966 $\left.\left(10^{-3} \mathrm{~mm}^{2} / \mathrm{s}\right)\right)$ and highest in the parietal cortex (mean=1.150 $\left.\left(10^{-3} \mathrm{~mm}^{2} / \mathrm{s}\right)\right)$. Age was significantly related to cortical MD, with a significant $(p<0.05)$ positive relationship in 29 of 33 ROls. Seventeen ROls showed a significant positive relationship between age and WM MD, and only 4 ROls showed a negative age relationship with cortical thickness. Average values for ROI measures as well as age and site effects are presented in the supplemental material (see Supplemental Table 1). There were significant phenotypic correlations and complete genetic overlap between all pairs of homologous ROIs in 
each hemisphere (see Supplemental Results). This pattern was consistent with previous findings regarding cortical thickness and surface area (Eyler et al., 2014; Kremen et al., 2010), supporting the use of bilateral averages for cortical MD.

\subsection{Heritability of cortical MD}

$\mathrm{MZ}$ and DZ cross-twin correlations, genetic and environmental components, as well as tests of significance for univariate parameters are presented in Table 1. Estimates of cross-twin correlations of cortical MD in MZ twins ranged from 0.41 in the parahippocampal cortex to 0.72 in the precuneus. Correlation estimates between DZ twins ranged from -0.19 in the entorhinal cortex to 0.50 in the postcentral gyrus. The heritability estimate $\left(a^{2}\right)$ of global cortical MD was 0.65. Heritability estimates of ROls ranged from 0.004 in the parahippocampal cortex to 0.69 in the lateral occipital cortex. In sum, cortical MD was significantly heritable in 21 of the 33 cortical ROls examined (Figure 1). The average of regional heritability estimates was highest in the occipital lobe (mean $\mathrm{a}^{2}=0.66$; range $=0.63-0.69$ ), followed by the frontal lobe (mean $\mathrm{a}^{2}=0.53$; range $=0.28-0.66)$, parietal lobe (mean $a^{2}=0.50$; range $\left.=0.22-0.65\right)$, temporal lobe (mean $a^{2}=0.45$; range $\left.=0.00-0.66\right)$, and the cingulate cortex (mean $a^{2}=0.38$; range $\left.=0.16-0.47\right)$. For all regions, $95 \% \mathrm{Cls}$ revealed that estimates of $\mathrm{C}$ were not significantly different from zero. To determine whether regional heritability remained after accounting for global MD, we also ran univariate models in which the global cortical MD was regressed out of each ROI. Cortical MD was significantly heritable in 19 of the 33 ROls examined, indicating the presence of residual genetic influences not accounted for by the global signal (Supplemental Table S2).

\subsection{Relationships between cortical MD and cortical thickness}

Phenotypic, genetic, and unique environmental correlations from the trivariate analysis of cortical MD, WM MD, and cortical thickness are presented in Table 2. No ROls showed any significant shared environment covariance between measures; therefore, these results are not displayed. Phenotypic correlations between cortical MD and thickness were all negative, and 
ranged from -0.04 in the temporal pole to -0.79 in the superior frontal gyrus. The $95 \% \mathrm{Cls}$ did not include zero in 30 of the 33 ROIs, indicating significant phenotypic correlations.

All genetic correlations between cortical MD and thickness were negative. The genetic correlations between cortical MD and thickness ranged from -0.08 in the temporal pole to -0.99 in the entorhinal cortex. These correlations were significantly different from zero in 13 of 33 ROls indicating the presence of some shared genetic influence between these two measures. The 95\% Cls revealed that genetic correlations between cortical MD and thickness were significantly different from $r_{g}=1$ in 29 of the 33 ROls, indicating at least some degree of independent genetic contributions to cortical MD and thickness in these regions. ROls with significant genetic correlations between cortical MD and thickness were distributed across the brain with no discernible spatial pattern (Figure 2). Thirty-two of the $33 \mathrm{ROIs}$ demonstrated a negative unique environmental correlation between cortical MD and thickness. Unique environmental correlations between cortical MD and thickness ranged from 0.01 to -0.72 , with 24 being significantly different from 0 (all negative correlations).

\subsection{Relationships between cortical MD and white matter MD}

All phenotypic correlations between cortical MD and WM MD were positive, ranging from 0.04 in the paracentral lobule to 0.80 in the medial orbitofrontal cortex. The phenotypic correlations were significant (i.e., $95 \%$ Cls did not include zero) in 31 out of 33 ROls.

All significant genetic correlations between cortical MD and WM MD were positive. There were significant genetic correlations in 8 of 33 ROls between cortical MD and WM MD, and Cls of 29 ROls did not include 1 , indicating the presence of unique genetic contributions to cortical MD when compared to WM MD in a large majority of ROls. ROls with significant genetic correlations between cortical MD and WM MD were also distributed across the brain with no discernible spatial pattern (Figure 3). Thirty ROIs showed positive unique environmental correlations between cortical MD and WM. Unique environmental correlations between cortical 
MD and WM MD ranged from -0.08 to 0.77 , with 19 being significantly different from 0 (all positive correlations).

\subsection{Relationships between cortical thickness and WM MD}

Although not a focus of this study, there were small, albeit significant, phenotypic correlations between cortical thickness and WM MD in 25 of 33 ROls. Of these, all but 2 were negative correlations. However, there were no significant genetic correlations between these measures in any ROI.

\section{Discussion}

The results from the current study provide strong evidence that cortical MD is genetically influenced. However, there was a considerable amount of variability in heritability estimates of individual ROIs (ranging from 0.004 to 0.69 ), and there did not appear to be a simple topographical pattern to these results. Thus, using global values of cortical MD may obscure regionally specific differences in the degree of genetic influence.

A majority of significant heritability estimates fell between 0.4 and 0.7 , which is broadly consistent with those found for other MRI measures of brain structure (i.e., cortical thickness and surface area), and dMRI measures of WM (Blokland et al., 2012; Chiang et al., 2009; Eyler et al., 2011b; Kochunov et al., 2010; Kremen et al., 2010). We found no evidence for significant effects of shared environmental influences, which is also consistent with previous findings of structural MRI measures from our group and others (Blokland et al., 2012; Kremen et al., 2010).

In much of the brain, variation in cortical MD is at least partly determined by genetic factors distinct from those that influence cortical thickness or WM MD. Cortical MD showed a significant phenotypic correlation with cortical thickness and WM MD in almost all ROls, yet significant genetic correlations were present in only a portion of these regions (13 of 33 ROls for cortical thickness and 8 of 33 ROls for WM MD). With the exception of the rostral middle frontal gyrus, these ROls exhibited a significant genetic correlation between cortical MD and either cortical thickness or WM MD, but not both. Therefore, although cortical MD is phenotypically correlated 
with both cortical thickness and WM MD, it constitutes an imaging phenotype that, for the most part, is genetically distinct from those two other phenotypes. It should also be noted that the majority of ROls demonstrated significant unique environmental correlations. While there are likely to be environmental factors underlying shared variance in the neurobiological substrates of these measures, this cannot be disentangled from correlated measurement error similarly affecting both imaging modalities. Thus, these results must be interpreted with caution.

There may be multiple underlying physiological processes that contribute to variation in the cortical MD signal. Increased water diffusion is expected to result from cellular degeneration due to breakdowns in cell and organelle membranes (Douaud et al., 2009). However, it has also been proposed that altered gray matter MD reflects astrocytosis or swelling in cells due to inflammation (Douaud et al., 2013; Ryan et al., 2013; Van Camp et al., 2012). A shift of astrocytes to a reactive state has been associated with AD pathogenesis (Steele and Robinson, 2012), thus more work is necessary to determine the relative sensitivity of cortical MD to disease-specific inflammatory processes versus inflammation more generally.

Variation in MD may also reflect the influence of cytotoxic or vasogenic edemas (Neil et al., 2002; Sundgren et al., 2004). In this context, it is important to note that changes in MD can be non-monotonic over time. Decreased diffusion is often apparent shortly after brain injury (although it may increase after vasogenic edema), and likely represents movement of water from extracellular to intracellular spaces. This is followed by pseudonormalization, a return to baseline levels of diffusion, and subsequent increased diffusion above baseline levels (Neil et al., 2002; Sundgren et al., 2004). Similar non-linear trajectories have been proposed in the progression of $A D$ and CJD. In both cases, dMRI signals indicate restricted diffusion (i.e., decreased MD), followed by increasing cortical and subcortical MD during later disease stages (Eisenmenger et al., 2015; Fortea et al., 2010; Jacobs et al., 2013; Ryan et al., 2013; Ukisu et al., 2005). The potentially heterogeneous sources of neurobiological substrates contributing to cortical MD, and the non-linear trajectories of this measure indicate that estimates of heritability 
may differ based on age group or disease status. Individuals at different stages of a given disease progression could exhibit markedly different patterns of change in cortical MD if nonlinear trajectories are not taken into account. Further longitudinal studies over a wide range of ages will be necessary to define potential differences in heritability across the lifetime.

Genetic correlations between cortical MD and cortical thickness may reflect processes that initially affect microstructural properties of cells and eventually manifest as morphological changes. GM volume and MD both show strong relationships with age (Benedetti et al., 2006), and have been proposed to measure either shrinkage of large neurons, or actual cell loss (Dickstein et al., 2007; Ni et al., 2010). It should be noted that the estimates of genetic correlation in the present study are derived from late middle-aged men whose brains have completed maturational change and are entering a period in which deleterious age and diseaserelated changes are increasingly likely to occur. Indeed, increasing cortical MD is not continuous across the lifespan but has been found to occur starting in middle age (Ni et al., 2010). To the extent that accumulating microstructural changes directly predict morphological changes, estimates of genetic overlap may increase with the onset of conditions with a genetic component that only exert their effect later in life. While the twin method is able to determine shared genetic variance, genetic association studies will be needed to determine the specific genes involved. Alternatively, accumulating environmental insults over the lifespan, such as head injuries, may drive covariance between these measures and result in apparently lower genetic correlations at older ages. Thus, it will be important to assess not only how microstructural and morphological measures correlate across the lifespan, but also how predictive one is of the other over time.

Of note, we chose to sample WM MD subjacent to the gray/white boundary $(0.8-2 \mathrm{~mm})$, and a large portion of this signal likely arises from intracortical $U$-fibers that connect adjacent gyri (Curnes et al., 1988; Kim et al., 2008). These values therefore act as a close proxy of potential WM contributions to dMRI signals in the cortical GM. Intracortical WM fibers are 
particularly relevant as they are some of the last to myelinate, and intracortical myelin is especially vulnerable to degeneration (Bartzokis, 2011; Bartzokis et al., 2007). AD-related neurofibrillary changes occur in regions that undergo late myelination (Braak and Braak, 1996; Braak et al., 2000), and increased cortical MD associated with multiple sclerosis has been proposed to reflect both direct and indirect effects of demyelination in the WM (Rovaris et al., 2006). Wallerian degeneration is another mechanism whereby altered measurements of cortical MD may be directly related to changes in myelinated WM. However, correlations do not necessarily indicate direct contributions of myelin to the cortical MD signal. Rather, factors such as amyloid deposition or neurofibrillary tangles may cause damage to nearby tissue, affecting WM and GM alike. Thus, as in the relationship between cortical MD and cortical thickness, there may be increased genetic correlations between cortical MD and WM MD in the presence of conditions with a genetic component that cause reductions in myelination or neuropathology with regional effects. Future studies will be needed to examine how correlations between cortical MD and WM MD differ as a function of disease status or direct measures of disease pathology (e.g., levels of CSF phosphorylated tau).

A few limitations of the current study should be addressed. The VETSA sample is composed solely of men, which may limit the generalizability of these results to the extent that the aging process is different in women. Regarding methodological issues, cortical MD is particularly susceptible to partial volume effects (PVE) due to the close proximity of CSF (Jeon et al., 2012; Weston et al., 2015). These effects may be exacerbated by any inaccuracies in coregistration if the boundaries of the cortical ribbon fall within CSF or WM. It is possible that the cortical thickness of a given region (and its susceptibility to PVE) may affect the covariance between cortical thickness and cortical MD. That is, regions with thinner cortex may have correspondingly high cortical MD if there is greater PVE from CSF. To minimize these effects, we sampled away from the boundaries of the cortical ribbon, which may be more susceptible to partial volume effects. A weighting function was used exclude or reduce the contribution from 
voxels with a low proportion of the tissue of interest. Additionally, we found no correlation between regional cortical thickness and the covariance between cortical thickness and cortical MD ( $r=-0.08, p=0.651$; see Supplemental Results for more details). Another limitation is that dMRI suffers from spatial distortions due to magnetic susceptibility artifacts, particularly in the frontal and temporal poles. Although the acquisition scheme and pre-processing steps were implemented to correct for this distortion, residual effects, such as spatially inhomogeneous blurring, will remain. With regards to the ACE model, this could have the effect of inflating the $E$ component (unique environment) and pushing down the A component (genetic influence). While the values of cortical MD within polar regions did not appear to be outliers (see Supplemental Table S1), heritability in some of these regions was not significant as indicated by confidence intervals that included 0 . Unfortunately, it is difficult to determine whether this is due to the effects of distortion or if it represents true regional variability, a phenomena found across most twin studies of imaging phenotypes (Blokland et al., 2012; Chen et al., 2012; Eyler et al., 2011b; Kremen et al., 2010; Panizzon et al., 2009). Additionally, the heritability estimate of global cortical MD was similar when temporal and frontal poles were excluded $\left(\mathrm{a}^{2}=0.62,95 \% \mathrm{Cl}=\right.$ $0.15-0.75)$. Lastly, the current study included data from two sites. While there did appear to be a mean level offset in values of MD, regressing out site effects produced similar distributions of values in each. It is also important to note that mean level change does not affect the results of the ACE model used in this study. The fundamental unit of analysis is the correlation between twins, and twin pairs were always scanned on the same scanner. Therefore, we do not believe that site significantly affected the results.

In summary, the current study provides evidence that cortical MD is heritable, and while it does exhibit some degree of shared genetic influence with WM MD and cortical thickness, it also has unique sources of genetic variance. Regional variation in these estimates indicates that global measures of cortical MD may obscure regional differences. Previous studies have found that cortical MD is related to age and may be sensitive to early stages of neurodegenerative 
disease or neuronal injury. Disease-related changes in this measure may precede changes in other MRI modalities, making it a potentially useful measure for earlier disease detection. The current findings lend support to the use of regional cortical MD as a phenotype in future genetic association studies and support further research into this measure as a biomarker of age and disease-related effects.

\section{Acknowledgments}

The content of this manuscript is the responsibility of the authors and does not represent official views of $\mathrm{NIA} / \mathrm{NIH}$, or the Veterans' Administration. Numerous organizations provided invaluable assistance in the conduct of the VET Registry, including: U.S. Department of Veterans Affairs, Department of Defense; National Personnel Records Center, National Archives and Records Administration; Internal Revenue Service; National Opinion Research Center; National Research Council, National Academy of Sciences; the Institute for Survey Research, Temple University. The authors gratefully acknowledge the continued cooperation of the twins and the efforts of many staff members. The study was supported by awards from the National Institutes of Health/National Institute on Aging [R01s AG018386, AG022381, AG022982, AG050595 to W.S.K.; R01 AG018384 to M.J.L.; R03 AG 046413 to C.E.F, and K08 AG047903 to M.S.P]. 


\section{References}

Abe, O., Yamasue, H., Aoki, S., Suga, M., Yamada, H., Kasai, K., Masutani, Y., Kato, N., Kato, N., Ohtomo, K., 2008. Aging in the CNS: Comparison of gray/white matter volume and diffusion tensor data. Neurobiology of Aging 29, 102-116.

Bartzokis, G., 2011. Alzheimer's disease as homeostatic responses to age-related myelin breakdown. Neurobiol Aging 32, 1341-1371.

Bartzokis, G., Lu, P.H., Mintz, J., 2007. Human brain myelination and amyloid beta deposition in Alzheimer's disease. Alzheimer's \& Dementia 3, 122-125.

Basser, P.J., Mattiello, J., LeBihan, D., 1994. MR diffusion tensor spectroscopy and imaging. Biophys J 66, 259-267.

Beaton, A.E., Tukey, J.W., 1974. The Fitting of Power Series, Meaning Polynomials, Illustrated on Band-Spectroscopic Data. Technometrics 16, 147-185.

Beaulieu, C., 2002. The basis of anisotropic water diffusion in the nervous system - a technical review. NMR in Biomedicine 15, 435-455.

Beaulieu, C., Does, M.D., Snyder, R.E., Allen, P.S., 1996. Changes in water diffusion due to Wallerian degeneration in peripheral nerve. Magn Reson Med 36, 627-631.

Benedetti, B., Charil, A., Rovaris, M., Judica, E., Valsasina, P., Sormani, M.P., Filippi, M., 2006. Influence of aging on brain gray and white matter changes assessed by conventional, MT, and DT MRI. Neurology 66, 535-539.

Blokland, G.A.M., de Zubicaray, G.I., McMahon, K.L., Wright, M.J., 2012. Genetic and Environmental Influences on Neuroimaging Phenotypes: A Meta-Analytical Perspective on Twin Imaging Studies. Twin Research and Human Genetics 15, 351-371.

Boker, S., Neale, M., Maes, H., Wilde, M., Spiegel, M., Brick, T., Spies, J., Estabrook, R., Kenny, S., Bates, T., Mehta, P., Fox, J., 2011. OpenMx: An Open Source Extended Structural Equation Modeling Framework. Psychometrika 76, 306-317.

Braak, H., Braak, E., 1991. Neuropathological stageing of Alzheimer-related changes. Acta Neuropathologica 82, 239-259.

Braak, H., Braak, E., 1996. Development of Alzheimer-related neurofibrillary changes in the neocortex inversely recapitulates cortical myelogenesis. Acta Neuropathologica 92, 197201.

Braak, H., Braak, E., 1998. Evolution of neuronal changes in the course of Alzheimer's disease. J Neural Transm Suppl 53, 127-140.

Braak, H., Del Tredici, K., Schultz, C., Braak, E., 2000. Vulnerability of select neuronal types to Alzheimer's disease. Ann N Y Acad Sci 924, 53-61.

Cercignani, M., Bozzali, M., Iannucci, G., Comi, G., Filippi, M., 2001. Magnetisation transfer ratio and mean diffusivity of normal appearing white and grey matter from patients with multiple sclerosis. Journal of Neurology, Neurosurgery \& Psychiatry 70, 311-317.

Concha, L., Livy, D.J., Beaulieu, C., Wheatley, B.M., Gross, D.W., 2010. In vivo diffusion tensor imaging and histopathology of the fimbria-fornix in temporal lobe epilepsy. The Journal of neuroscience : the official journal of the Society for Neuroscience 30, 996-1002.

Chang, H., Fitzpatrick, J.M., 1992. A technique for accurate magnetic resonance imaging in the presence of field inhomogeneities. IEEE Trans Med Imaging 11, 319-329.

Chen, C.H., Fiecas, M., Gutiérrez, E.D., Panizzon, M.S., Eyler, L.T., Vuoksimaa, E., Thompson, W.K., Fennema-Notestine, C., Hagler, D.J., Jernigan, T.L., Neale, M.C., Franz, C.E., Lyons, M.J., Fischl, B., Tsuang, M.T., Dale, A.M., Kremen, W.S., 2013. Genetic topography of brain morphology. Proceedings of the National Academy of Sciences 110, 17089-17094.

Chen, C.H., Gutierrez, E.D., Thompson, W., Panizzon, M.S., Jernigan, T.L., Eyler, L.T., Fennema-Notestine, C., Jak, A.J., Neale, M.C., Franz, C.E., Lyons, M.J., Grant, M.D., Fischl, B., Seidman, L.J., Tsuang, M.T., Kremen, W.S., Dale, A.M., 2012. Hierarchical Genetic Organization of Human Cortical Surface Area. Science 335, 1634-1636. 
Chiang, M.-C., Barysheva, M., Shattuck, D.W., Lee, A.D., Madsen, S.K., Avedissian, C., Klunder, A.D., Toga, A.W., McMahon, K.L., de Zubicaray, G.I., Wright, M.J., Srivastava, A., Balov, N., Thompson, P.M., 2009. Genetics of Brain Fiber Architecture and Intellectual Performance. The Journal of Neuroscience 29, 2212-2224.

Curnes, J.T., Burger, P.C., Djang, W.T., Boyko, O.B., 1988. MR imaging of compact white matter pathways. American Journal of Neuroradiology 9, 1061-1068.

Dale, A.M., Fischl, B., Sereno, M.I., 1999. Cortical Surface-Based Analysis: I. Segmentation and Surface Reconstruction. Neuroimage 9, 179-194.

Demaerel, P., Heiner, L., Robberecht, W., Sciot, R., Wilms, G., 1999. Diffusion-weighted MRI in sporadic Creutzfeldt-Jakob disease. Neurology 52, 205-208.

Desikan, R.S., Segonne, F., Fischl, B., Quinn, B.T., Dickerson, B.C., Blacker, D., Buckner, R.L., Dale, A.M., Maguire, R.P., Hyman, B.T., Albert, M.S., Killiany, R.J., 2006. An automated labeling system for subdividing the human cerebral cortex on MRI scans into gyral based regions of interest. Neuroimage 31, 968-980.

Dickstein, D.L., Kabaso, D., Rocher, A.B., Luebke, J.I., Wearne, S.L., Hof, P.R., 2007. Changes in the structural complexity of the aged brain. Aging cell 6, 275-284.

Douaud, G., Behrens, T.E., Poupon, C., Cointepas, Y., Jbabdi, S., Gaura, V., Golestani, N., Krystkowiak, P., Verny, C., Damier, P., Bachoud-Lévi, A.-C., Hantraye, P., Remy, P., 2009. In vivo evidence for the selective subcortical degeneration in Huntington's disease. Neuroimage 46, 958-966.

Douaud, G., Menke, R.A.L., Gass, A., Monsch, A.U., Rao, A., Whitcher, B., Zamboni, G., Matthews, P.M., Sollberger, M., Smith, S., 2013. Brain Microstructure Reveals Early Abnormalities more than Two Years prior to Clinical Progression from Mild Cognitive Impairment to Alzheimer's Disease. The Journal of Neuroscience 33, 2147-2155.

Eaves, L.J., Last, K.A., Young, P.A., Martin, N.G., 1978. Model-fitting approaches to the analysis of human behavior. Heredity $41,249-320$.

Eickhoff, S., Walters, N.B., Schleicher, A., Kril, J., Egan, G.F., Zilles, K., Watson, J.D., Amunts, K., 2005. High-resolution MRI reflects myeloarchitecture and cytoarchitecture of human cerebral cortex. Hum Brain Mapp 24, 206-215.

Eisenmenger, L., Porter, M., Carswell, C.J., et al., 2015. EVolution of diffusion-weighted magnetic resonance imaging signal abnormality in sporadic creutzfeldt-jakob disease, with histopathological correlation. JAMA Neurology, 1-9.

Eyler, L.T., Prom-Wormley, E., Fennema-Notestine, C., Panizzon, M.S., Neale, M.C., Jernigan, T.L., Fischl, B., Franz, C.E., Lyons, M.J., Stevens, A., Pacheco, J., Perry, M.E., Schmitt, J.E., Spitzer, N.C., Seidman, L.J., Thermenos, H.W., Tsuang, M.T., Dale, A.M., Kremen, W.S., 2011a. Genetic patterns of correlation among subcortical volumes in humans: results from a magnetic resonance imaging twin study. Hum Brain Mapp 32, 641-653.

Eyler, L.T., Prom-Wormley, E., Panizzon, M.S., Kaup, A.R., Fennema-Notestine, C., Neale, M.C., Jernigan, T.L., Fischl, B., Franz, C.E., Lyons, M.J., Grant, M., Stevens, A., Pacheco, J., Perry, M.E., Schmitt, J.E., Seidman, L.J., Thermenos, H.W., Tsuang, M.T., Chen, C.-H., Thompson, W.K., Jak, A., Dale, A.M., Kremen, W.S., 2011b. Genetic and Environmental Contributions to Regional Cortical Surface Area in Humans: A Magnetic Resonance Imaging Twin Study. Cerebral Cortex 21, 2313-2321.

Eyler, L.T., Vuoksimaa, E., Panizzon, M.S., Fennema-Notestine, C., Neale, M.C., Chen, C.-H., Jak, A., Franz, C.E., Lyons, M.J., Thompson, W.K., Spoon, K.M., Fischl, B., Dale, A.M., Kremen, W.S., 2014. Conceptual and Data-based Investigation of Genetic Influences and Brain Asymmetry: A Twin Study of Multiple Structural Phenotypes. Journal of Cognitive Neuroscience 26, 1100-1117.

Fellgiebel, A., Dellani, P.R., Greverus, D., Scheurich, A., Stoeter, P., Müller, M.J., 2006. Predicting conversion to dementia in mild cognitive impairment by volumetric and diffusivity measurements of the hippocampus. Psychiatry Research: Neuroimaging 146, 283-287. 
Fellgiebel, A., Wille, P., Müller, M.J., Winterer, G., Scheurich, A., Vucurevic, G., Schmidt, L.G., Stoeter, P., 2004. Ultrastructural Hippocampal and White Matter Alterations in Mild Cognitive Impairment: A Diffusion Tensor Imaging Study. Dementia and Geriatric Cognitive Disorders 18, 101-108.

Fischl, B., Dale, A.M., 2000. Measuring the thickness of the human cerebral cortex from magnetic resonance images. Proc Natl Acad Sci U S A 97, 11050-11055.

Fischl, B., Sereno, M.I., Dale, A.M., 1999. Cortical surface-based analysis. II: Inflation, flattening, and a surface-based coordinate system. Neuroimage 9, 195-207.

Fischl, B., van der Kouwe, A., Destrieux, C., Halgren, E., Segonne, F., Salat, D.H., Busa, E., Seidman, L.J., Goldstein, J., Kennedy, D., Caviness, V., Makris, N., Rosen, B., Dale, A.M., 2004. Automatically parcellating the human cerebral cortex. Cereb Cortex 14, 11-22.

Fortea, J., Sala-Llonch, R., Bartres-Faz, D., Bosch, B., Llado, A., Bargallo, N., Molinuevo, J.L., Sanchez-Valle, R., 2010. Increased cortical thickness and caudate volume precede atrophy in PSEN1 mutation carriers. J Alzheimers Dis 22, 909-922.

Fraidakis, M., Klason, T., Cheng, H., Olson, L., Spenger, C., 1998. High-resolution MRI of intact and transected rat spinal cord. Exp Neurol 153, 299-312.

Hagler, D.J., Jr., Ahmadi, M.E., Kuperman, J., Holland, D., McDonald, C.R., Halgren, E., Dale, A.M., 2009. Automated white-matter tractography using a probabilistic diffusion tensor atlas: Application to temporal lobe epilepsy. Hum Brain Mapp 30, 1535-1547.

Holland, D., Kuperman, J.M., Dale, A.M., 2010. Efficient correction of inhomogeneous static magnetic field-induced distortion in Echo Planar Imaging. Neuroimage 50, 175-183.

Jack, C.R., Knopman, D.S., Jagust, W.J., Petersen, R.C., Weiner, M.W., Aisen, P.S., Shaw, L.M., Vemuri, P., Wiste, H.J., Weigand, S.D., Lesnick, T.G., Pankratz, V.S., Donohue, M.C., Trojanowski, J.Q., 2013. Tracking pathophysiological processes in Alzheimer's disease: an updated hypothetical model of dynamic biomarkers. The Lancet Neurology 12, 207-216.

Jack, C.R., Lowe, V.J., Senjem, M.L., Weigand, S.D., Kemp, B.J., Shiung, M.M., Knopman, D.S., Boeve, B.F., Klunk, W.E., Mathis, C.A., Petersen, R.C., 2008. 11C PiB and structural $\mathrm{MRI}$ provide complementary information in imaging of Alzheimer's disease and amnestic mild cognitive impairment. Brain 131, 665-680.

Jacobs, H.I.L., van Boxtel, M.P.J., Gronenschild, E.H.B.M., Uylings, H.B.M., Jolles, J., Verhey, F.R.J., 2013. Decreased gray matter diffusivity: A potential early Alzheimer's disease biomarker? Alzheimer's \& Dementia 9, 93-97.

Jeon, T., Mishra, V., Uh, J., Weiner, M., Hatanpaa, K.J., White, C.L., 3rd, Zhao, Y.D., Lu, H., Diaz-Arrastia, R., Huang, H., 2012. Regional changes of cortical mean diffusivities with aging after correction of partial volume effects. Neuroimage 62, 1705-1716.

Jovicich, J., Czanner, S., Greve, D., Haley, E., van der Kouwe, A., Gollub, R., Kennedy, D., Schmitt, F., Brown, G., Macfall, J., Fischl, B., Dale, A., 2006. Reliability in multi-site structural MRI studies: effects of gradient non-linearity correction on phantom and human data. Neuroimage 30, 436-443.

Kantarci, K., Avula, R., Senjem, M.L., Samikoglu, A.R., Zhang, B., Weigand, S.D., Przybelski, S.A., Edmonson, H.A., Vemuri, P., Knopman, D.S., Ferman, T.J., Boeve, B.F., Petersen, R.C., Jack, C.R., 2010. Dementia with Lewy bodies and Alzheimer disease: Neurodegenerative patterns characterized by DTI. Neurology 74, 1814-1821.

Kantarci, K., Jack, C.R., Xu, Y.C., Campeau, N.G., O'Brien, P.C., Smith, G.E., Ivnik, R.J., Boeve, B.F., Kokmen, E., Tangalos, E.G., Petersen, R.C., 2001. Mild Cognitive Impairment and Alzheimer Disease: Regional Diffusivity of Water. Radiology 219, 101-107.

Kantarci, K., Petersen, R.C., Boeve, B.F., Knopman, D.S., Weigand, S.D., O'Brien, P.C., Shiung, M.M., Smith, G.E., Ivnik, R.J., Tangalos, E.G., Jack, C.R., Jr., 2005. DWI predicts future progression to Alzheimer disease in amnestic mild cognitive impairment. Neurology $64,902-904$. 
Kim, K.W., MacFall, J.R., Payne, M.E., 2008. Classification of White Matter Lesions on Magnetic Resonance Imaging in Elderly Persons. Biological Psychiatry 64, 273-280.

Kochunov, P., Glahn, D.C., Lancaster, J.L., Winkler, A.M., Smith, S., Thompson, P.M., Almasy, L., Duggirala, R., Fox, P.T., Blangero, J., 2010. Genetics of microstructure of cerebral white matter using diffusion tensor imaging. Neuroimage 53, 1109-1116.

Kremen, W.S., Franz, C.E., Lyons, M.J., 2013. VETSA: the Vietnam Era Twin Study of Aging. Twin research and human genetics: the official journal of the International Society for Twin Studies 16, 399-402.

Kremen, W.S., Prom-Wormley, E., Panizzon, M.S., Eyler, L.T., Fischl, B., Neale, M.C., Franz, C.E., Lyons, M.J., Pacheco, J., Perry, M.E., Stevens, A., Schmitt, J.E., Grant, M.D., Seidman, L.J., Thermenos, H.W., Tsuang, M.T., Eisen, S.A., Dale, A.M., FennemaNotestine, C., 2010. Genetic and environmental influences on the size of specific brain regions in midlife: The VETSA MRI study. Neuroimage 49, 1213-1223.

Kremen, W.S., Thompson-Brenner, H., Leung, Y.J., Grant, M.D., Franz, C.E., Eisen, S.A., Jacobson, K.C., Boake, C., Lyons, M.J., 2006. Genes, environment, and time: The Vietnam Era Twin Study of Aging (VETSA). Twin Research and Human Genetics 9, 1009-1022.

Le Bihan, D., Mangin, J.F., Poupon, C., Clark, C.A., Pappata, S., Molko, N., Chabriat, H., 2001. Diffusion tensor imaging: concepts and applications. J Magn Reson Imaging 13, 534-546.

Leemans, A., Jones, D.K., 2009. The B-matrix must be rotated when correcting for subject motion in DTI data. Magn Reson Med 61, 1336-1349.

McEvoy, L.K., Fennema-Notestine, C., Eyler, L.T., Franz, C.E., Hagler, D.J., Jr., Lyons, M.J., Panizzon, M.S., Rinker, D.A., Dale, A.M., Kremen, W.S., 2015. Hypertension-Related Alterations in White Matter Microstructure Detectable in Middle Age. Hypertension 66, 317323.

Molinuevo, J.L., Ripolles, P., Simo, M., Llado, A., Olives, J., Balasa, M., Antonell, A., RodriguezFornells, A., Rami, L., 2014. White matter changes in preclinical Alzheimer's disease: a magnetic resonance imaging-diffusion tensor imaging study on cognitively normal older people with positive amyloid beta protein 42 levels. Neurobiol Aging 35, 2671-2680.

Morgan PS, Bowtell RW, Mclntyre DJ, Worthington BS (2004) Correction of spatial distortion in EPI due to inhomogeneous static magnetic fields using the reversed gradient method. $J$ Magn Reson Imaging 19:499-507.

Müller, M.J., Greverus, D., Dellani, P.R., Weibrich, C., Wille, P.R., Scheurich, A., Stoeter, P., Fellgiebel, A., 2005. Functional implications of hippocampal volume and diffusivity in mild cognitive impairment. Neuroimage 28, 1033-1042.

Neale, M.C., Cardon, L.R., 1992. Methodology for genetic studies of twins and families. Kluwer Academic Publishers, Dordrecht, The Netherlands.

Neil, J., Miller, J., Mukherjee, P., Hüppi, P.S., 2002. Diffusion tensor imaging of normal and injured developing human brain - a technical review. NMR in Biomedicine 15, 543-552.

Ni, J.M., Chen, S., Liu, J.J., Huang, G., Shen, T.Z., Chen, X.R., 2010. Regional diffusion changes of cerebral grey matter during normal aging--a fluid-inversion prepared diffusion imaging study. Eur J Radiol 75, 134-138.

Panizzon, M.S., Fennema-Notestine, C., Eyler, L.T., Jernigan, T.L., Prom-Wormley, E., Neale, M., Jacobson, K., Lyons, M.J., Grant, M.D., Franz, C.E., Xian, H., Tsuang, M., Fischl, B., Seidman, L., Dale, A., Kremen, W.S., 2009. Distinct Genetic Influences on Cortical Surface Area and Cortical Thickness. Cerebral Cortex 19, 2728-2735.

Panizzon, M.S., Fennema-Notestine, C., Kubarych, T.S., Chen, C.-H., Eyler, L.T., Fischl, B., Franz, C.E., Grant, M.D., Hamza, S., Jak, A., Jernigan, T.L., Lyons, M.J., Neale, M.C., Prom-Wormley, E.C., Seidman, L., Tsuang, M.T., Wu, H., Xian, H., Dale, A.M., Kremen, W.S., 2012. Genetic and environmental influences of white and gray matter signal contrast: A new phenotype for imaging genetics? Neuroimage 60, 1686-1695. 
Paus, T., 2005. Mapping brain maturation and cognitive development during adolescence. Trends Cogn Sci 9, 60-68.

Pierpaoli, C., Barnett, A., Pajevic, S., Chen, R., Penix, L.R., Virta, A., Basser, P., 2001. Water diffusion changes in Wallerian degeneration and their dependence on white matter architecture. Neurolmage 13, 1174-1185.

Pierpaoli, C., Jezzard, P., Basser, P.J., Barnett, A., Di Chiro, G., 1996. Diffusion tensor MR imaging of the human brain. Radiology 201, 637-648.

Ray, K.M., Wang, H., Chu, Y., Chen, Y.F., Bert, A., Hasso, A.N., Su, M.Y., 2006. Mild cognitive impairment: apparent diffusion coefficient in regional gray matter and white matter structures. Radiology 241, 197-205.

Rimol, L.M., Panizzon, M.S., Fennema-Notestine, C., Eyler, L.T., Fischl, B., Franz, C.E., Hagler, D.J., Lyons, M.J., Neale, M.C., Pacheco, J., Perry, M.E., Schmitt, J.E., Grant, M.D., Seidman, L.J., Thermenos, H.W., Tsuang, M.T., Eisen, S.A., Kremen, W.S., Dale, A.M., 2010. Cortical Thickness is Influenced by Regionally-Specific Genetic Factors. Biological Psychiatry 67, 493-499.

Rovaris, M., Judica, E., Gallo, A., Benedetti, B., Sormani, M.P., Caputo, D., Ghezzi, A., Montanari, E., Bertolotto, A., Mancardi, G., Bergamaschi, R., Martinelli, V., Comi, G., Filippi, M., 2006. Grey matter damage predicts the evolution of primary progressive multiple sclerosis at 5 years. Brain 129, 2628-2634.

Ryan, N.S., Keihaninejad, S., Shakespeare, T.J., Lehmann, M., Crutch, S.J., Malone, I.B., Thornton, J.S., Mancini, L., Hyare, H., Yousry, T., Ridgway, G.R., Zhang, H., Modat, M., Alexander, D.C., Rossor, M.N., Ourselin, S., Fox, N.C., 2013. Magnetic resonance imaging evidence for presymptomatic change in thalamus and caudate in familial Alzheimer's disease. Brain 136, 1399-1414.

Salat, D.H., Lee, S.Y., van der Kouwe, A.J., Greve, D.N., Fischl, B., Rosas, H.D., 2009. Ageassociated alterations in cortical gray and white matter signal intensity and gray to white matter contrast. Neuroimage 48, 21-28.

Salat, D.H., Tuch, D.S., Greve, D.N., van der Kouwe, A.J.W., Hevelone, N.D., Zaleta, A.K., Rosen, B.R., Fischl, B., Corkin, S., Rosas, H.D., Dale, A.M., 2005. Age-related alterations in white matter microstructure measured by diffusion tensor imaging. Neurobiology of Aging 26, 1215-1227.

Schoeneborn, C.A., Heyman, K.M., 2009. Health characteristics of adults aged 55 years and over: United States, 2004-2007. National Health Statistics Reports; no. 16. National Health Statistics Reports. National Center for Health Statistics, Hyattsville, MD.

Scola, E., Bozzali, M., Agosta, F., Magnani, G., Franceschi, M., Sormani, M.P., Cercignani, M., Pagani, E., Falautano, M., Filippi, M., Falini, A., 2010. A diffusion tensor MRI study of patients with $\mathrm{MCl}$ and $\mathrm{AD}$ with a 2-year clinical follow-up. Journal of Neurology, Neurosurgery \& Psychiatry 81, 798-805.

Sled, J.G., Zijdenbos, A.P., Evans, A.C., 1998. A nonparametric method for automatic correction of intensity nonuniformity in MRI data. IEEE Trans Med Imaging 17, 87-97.

Song, S.-K., Sun, S.-W., Ju, W.-K., Lin, S.-J., Cross, A.H., Neufeld, A.H., 2003. Diffusion tensor imaging detects and differentiates axon and myelin degeneration in mouse optic nerve after retinal ischemia. Neuroimage 20, 1714-1722.

Song, S.-K., Sun, S.-W., Ramsbottom, M.J., Chang, C., Russell, J., Cross, A.H., 2002. Dysmyelination Revealed through MRI as Increased Radial (but Unchanged Axial) Diffusion of Water. Neuroimage 17, 1429-1436.

Song, S.K., Kim, J.H., Lin, S.J., Brendza, R.P., Holtzman, D.M., 2004. Diffusion tensor imaging detects age-dependent white matter changes in a transgenic mouse model with amyloid deposition. Neurobiol Dis 15, 640-647.

Steele, M.L., Robinson, S.R., 2012. Reactive astrocytes give neurons less support: implications for Alzheimer's disease. Neurobiology of Aging 33, 423.e421-423.e413. 
Sun, S.-W., Song, S.-K., Harms, M.P., Lin, S.-J., Holtzman, D.M., Merchant, K.M., Kotyk, J.J., 2005. Detection of age-dependent brain injury in a mouse model of brain amyloidosis associated with Alzheimer's disease using magnetic resonance diffusion tensor imaging. Experimental Neurology 191, 77-85.

Sundgren, P.C., Dong, Q., Gomez-Hassan, D., Mukherji, S.K., Maly, P., Welsh, R., 2004. Diffusion tensor imaging of the brain: review of clinical applications. Neuroradiology 46, 339350.

Ukisu, R., Kushihashi, T., Kitanosono, T., Fujisawa, H., Takenaka, H., Ohgiya, Y., Gokan, T., Munechika, H., 2005. Serial diffusion-weighted MRI of Creutzfeldt-Jakob disease. AJR Am J Roentgenol 184, 560-566.

Van Camp, N., Blockx, I., Camón, L., de Vera, N., Verhoye, M., Veraart, J., Van Hecke, W., Martínez, E., Soria, G., Sijbers, J., Planas, A.M., Van der Linden, A., 2012. A complementary diffusion tensor imaging (DTI)-histological study in a model of Huntington's disease. Neurobiology of Aging 33, 945-959.

Wells, W.M., 3rd, Viola, P., Atsumi, H., Nakajima, S., Kikinis, R., 1996. Multi-modal volume registration by maximization of mutual information. Med Image Anal 1, 35-51.

Weston, P.S., Simpson, I.J., Ryan, N.S., Ourselin, S., Fox, N.C., 2015. Diffusion imaging changes in grey matter in Alzheimer's disease: a potential marker of early neurodegeneration. Alzheimer's Research \& Therapy 7, 47.

Winkler, A.M., Sabuncu, M.R., Yeo, B.T., Fischl, B., Greve, D.N., Kochunov, P., Nichols, T.E., Blangero, J., Glahn, D.C., 2012. Measuring and comparing brain cortical surface area and other areal quantities. Neuroimage 61, 1428-1443.

Zerr, I., Kallenberg, K., Summers, D.M., Romero, C., Taratuto, A., Heinemann, U., Breithaupt, M., Varges, D., Meissner, B., Ladogana, A., Schuur, M., Haik, S., Collins, S.J., Jansen, G.H., Stokin, G.B., Pimentel, J., Hewer, E., Collie, D., Smith, P., Roberts, H., Brandel, J.P., van Duijn, C., Pocchiari, M., Begue, C., Cras, P., Will, R.G., Sanchez-Juan, P., 2009. Updated clinical diagnostic criteria for sporadic Creutzfeldt-Jakob disease. Brain 132, 26592668.

Zhuang, J., Hrabe, J., Kangarlu, A., Xu, D., Bansal, R., Branch, C.A., Peterson, B.S., 2006. Correction of eddy-current distortions in diffusion tensor images using the known directions and strengths of diffusion gradients. J Magn Reson Imaging 24, 1188-1193. 


\section{Figures \& Tables}

Table 1. Univariate ACE model for cortical mean diffusivity.

\begin{tabular}{|c|c|c|c|c|c|c|c|c|}
\hline \multirow[b]{2}{*}{ Region of Interest } & \multirow[b]{2}{*}{$\mathrm{r}_{\mathrm{MZ}}$} & \multirow[b]{2}{*}{$\mathrm{r}_{\mathrm{DZ}}$} & \multicolumn{6}{|c|}{ Standardized variance components } \\
\hline & & & $a^{2}$ & $95 \% \mathrm{CI}$ & $c^{2}$ & $95 \% \mathrm{CI}$ & $\mathrm{e}^{2}$ & $95 \% \mathrm{CI}$ \\
\hline Global Mean & 0.70 & 0.30 & 0.65 & $(0.19 ; 0.75)$ & 0.00 & $(0.00 ; 0.42)$ & 0.35 & $(0.25 ; 0.47)$ \\
\hline \multicolumn{9}{|l|}{ Frontal lobe } \\
\hline Superior frontal gyrus & 0.67 & 0.36 & 0.28 & $(0.00 ; 0.70)$ & 0.33 & $(0.00 ; 0.65)$ & 0.39 & $(0.29 ; 0.52)$ \\
\hline Rostral middle frontal gyrus & 0.68 & 0.23 & 0.65 & $(0.25 ; 0.74)$ & 0.00 & $(0.00 ; 0.36)$ & 0.35 & $(0.26 ; 0.48)$ \\
\hline Caudal middle frontal gyrus & 0.67 & 0.32 & 0.62 & $(0.14 ; 0.75)$ & 0.04 & $(0.00 ; 0.47)$ & 0.35 & $(0.25 ; 0.48)$ \\
\hline Lateral orbitofrontal cortex & 0.63 & 0.18 & 0.61 & $(0.28 ; 0.72)$ & 0.00 & $(0.00 ; 0.27)$ & 0.39 & $(0.28 ; 0.54)$ \\
\hline Medial orbitofrontal cortex & 0.49 & 0.19 & 0.48 & $(0.00 ; 0.61)$ & 0.00 & $(0.00 ; 0.42)$ & 0.52 & $(0.39 ; 0.70)$ \\
\hline Pars opercularis & 0.72 & 0.22 & 0.66 & $(0.28 ; 0.75)$ & 0.00 & $(0.00 ; 0.35)$ & 0.34 & $(0.25 ; 0.46)$ \\
\hline Pars orbitalis & 0.57 & 0.10 & 0.57 & $(0.25 ; 0.69)$ & 0.00 & $(0.00 ; 0.26)$ & 0.43 & $(0.31 ; 0.60)$ \\
\hline Pars triangularis & 0.68 & 0.13 & 0.63 & $(0.33 ; 0.73)$ & 0.00 & $(0.00 ; 0.26)$ & 0.37 & $(0.27 ; 0.51)$ \\
\hline Frontal pole & 0.51 & 0.38 & 0.48 & $(0.00 ; 0.69)$ & 0.09 & $(0.00 ; 0.47)$ & 0.43 & $(0.31 ; 0.61)$ \\
\hline Precentral gyrus & 0.59 & 0.27 & 0.55 & $(0.03 ; 0.68)$ & 0.02 & $(0.00 ; 0.46)$ & 0.44 & $(0.32 ; 0.59)$ \\
\hline Paracentral lobule & 0.72 & 0.48 & 0.34 & $(0.00 ; 0.75)$ & 0.35 & $(0.00 ; 0.67)$ & 0.31 & $(0.23 ; 0.43)$ \\
\hline \multicolumn{9}{|l|}{ Cingulate cortex } \\
\hline Rostral anterior cingulate cortex & 0.53 & 0.17 & 0.47 & $(0.00 ; 0.59)$ & 0.00 & $(0.00 ; 0.42)$ & 0.53 & $(0.41 ; 0.69)$ \\
\hline Caudal anterior cingulate cortex & 0.51 & 0.46 & 0.16 & $(0.00 ; 0.61)$ & 0.34 & $(0.00 ; 0.58)$ & 0.49 & $(0.36 ; 0.66)$ \\
\hline Posterior cingulate cortex & 0.59 & 0.35 & 0.42 & $(0.00 ; 0.66)$ & 0.12 & $(0.00 ; 0.53)$ & 0.45 & $(0.34 ; 0.61)$ \\
\hline Isthmus cingulate cortex & 0.51 & 0.13 & 0.47 & $(0.08 ; 0.61)$ & 0.00 & $(0.00 ; 0.32)$ & 0.53 & $(0.39 ; 0.70)$ \\
\hline \multicolumn{9}{|l|}{ Parietal lobe } \\
\hline Superior parietal cortex & 0.71 & 0.44 & 0.41 & $(0.01 ; 0.75)$ & 0.27 & $(0.00 ; 0.61)$ & 0.33 & $(0.24 ; 0.45)$ \\
\hline Inferior parietal cortex & 0.65 & 0.29 & 0.59 & $(0.09 ; 0.71)$ & 0.02 & $(0.00 ; 0.46)$ & 0.39 & $(0.29 ; 0.54)$ \\
\hline Supramarginal gyrus & 0.69 & 0.15 & 0.63 & $(0.33 ; 0.73)$ & 0.00 & $(0.00 ; 0.27)$ & 0.37 & $(0.27 ; 0.50)$ \\
\hline Precuneus & 0.72 & 0.35 & 0.65 & $(0.21 ; 0.77)$ & 0.04 & $(0.00 ; 0.44)$ & 0.31 & $(0.23 ; 0.43)$ \\
\hline Postcentral gyrus & 0.61 & 0.50 & 0.22 & $(0.00 ; 0.68)$ & 0.38 & $(0.00 ; 0.65)$ & 0.40 & $(0.29 ; 0.54)$ \\
\hline \multicolumn{9}{|l|}{ Occipital lobe } \\
\hline Lingual gyrus & 0.68 & 0.23 & 0.63 & $(0.26 ; 0.73)$ & 0.00 & $(0.00 ; 0.32)$ & 0.37 & $(0.27 ; 0.51)$ \\
\hline Pericalcarine cortex & 0.67 & 0.34 & 0.63 & $(0.18 ; 0.74)$ & 0.01 & $(0.00 ; 0.41)$ & 0.36 & $(0.26 ; 0.49)$ \\
\hline Cuneus & 0.71 & 0.29 & 0.69 & $(0.33 ; 0.77)$ & 0.00 & $(0.00 ; 0.32)$ & 0.31 & $(0.23 ; 0.44)$ \\
\hline Lateral occipital cortex & 0.72 & 0.21 & 0.69 & $(0.40 ; 0.78)$ & 0.00 & $(0.00 ; 0.26)$ & 0.31 & $(0.22 ; 0.44)$ \\
\hline \multicolumn{9}{|l|}{ Temporal lobe } \\
\hline Superior temporal gyrus & 0.68 & 0.43 & 0.40 & $(0.00 ; 0.73)$ & 0.24 & $(0.00 ; 0.60)$ & 0.36 & $(0.26 ; 0.49)$ \\
\hline Middle temporal gyrus & 0.65 & 0.27 & 0.62 & $(0.22 ; 0.72)$ & 0.00 & $(0.00 ; 0.35)$ & 0.38 & $(0.28 ; 0.52)$ \\
\hline
\end{tabular}




\begin{tabular}{|c|c|c|c|c|c|c|c|c|}
\hline Inferior temporal gyrus & 0.53 & 0.06 & 0.51 & $(0.12 ; 0.65)$ & 0.00 & $(0.00 ; 0.32)$ & 0.49 & $(0.35 ; 0.67)$ \\
\hline Transverse temporal cortex & 0.71 & 0.11 & 0.66 & $(0.43 ; 0.75)$ & 0.00 & $(0.00 ; 0.19)$ & 0.34 & $(0.25 ; 0.47)$ \\
\hline Banks of the sup. temporal sulcus & 0.72 & 0.12 & 0.66 & $(0.43 ; 0.76)$ & 0.00 & $(0.00 ; 0.20)$ & 0.34 & $(0.24 ; 0.47)$ \\
\hline Entorhinal cortex & 0.42 & -0.19 & 0.45 & $(0.15 ; 0.64)$ & 0.00 & $(0.00 ; 0.15)$ & 0.55 & $(0.36 ; 0.83)$ \\
\hline Parahippocampal cortex & 0.41 & 0.37 & 0.00 & $(0.00 ; 0.53)$ & 0.39 & $(0.00 ; 0.53)$ & 0.60 & $(0.45 ; 0.76)$ \\
\hline Fusiform gyrus & 0.48 & 0.21 & 0.31 & $(0.00 ; 0.56)$ & 0.11 & $(0.00 ; 0.49)$ & 0.58 & $(0.44 ; 0.75)$ \\
\hline Temporal pole & 0.42 & 0.34 & 0.40 & $(0.00 ; 0.66)$ & 0.13 & $(0.00 ; 0.51)$ & 0.48 & $(0.34 ; 0.69)$ \\
\hline
\end{tabular}

$r_{M Z}=$ correlation between monozygotic twins; $r_{D Z}=$ correlation between dizygotic twins; $a^{2}=$ additive genetic influences; $c^{2}=$ shared/common environmental influences; $\mathrm{e}^{2}=$ unique environmental influences; $95 \% \mathrm{Cl}=$ corrected $95 \%$ confidence intervals. 
Table 2. Trivariate ACE model for cortical mean diffusivity, cortical thickness, and WM mean diffusivity.

\begin{tabular}{|c|c|c|c|c|c|c|c|c|c|c|c|c|}
\hline \multirow[b]{2}{*}{ Region of interest } & \multicolumn{4}{|c|}{ Phenotypic correlations } & \multicolumn{4}{|c|}{ Genetic correlations } & \multicolumn{4}{|c|}{ Unique environment correlations } \\
\hline & $\begin{array}{c}\mathrm{r}_{\mathrm{p}} \\
(\mathrm{CT}- \\
\mathrm{CMD}) \\
\end{array}$ & $95 \% \mathrm{CI}$ & $\begin{array}{c}\mathrm{r}_{\mathrm{p}} \\
\text { (WMMD- } \\
\text { CMD) }\end{array}$ & $95 \% \mathrm{CI}$ & $\begin{array}{c}r_{\mathrm{g}} \\
(\mathrm{CT}- \\
\mathrm{CMD}) \\
\end{array}$ & $95 \% \mathrm{CI}$ & $\begin{array}{c}r_{g} \\
\text { (WMMD- } \\
\text { CMD) }\end{array}$ & $95 \% \mathrm{CI}$ & $\begin{array}{c}\mathrm{r}_{\mathrm{e}} \\
(\mathrm{CT}- \\
\mathrm{CMD}) \\
\end{array}$ & $95 \% \mathrm{CI}$ & $\begin{array}{c}\mathrm{r}_{\mathrm{e}} \\
\text { (WMMD- } \\
\text { CMD) }\end{array}$ & $95 \% \mathrm{CI}$ \\
\hline Global Mean & -0.55 & $(-0.62 ;-0.46)$ & 0.47 & $(0.38 ; 0.55)$ & -0.51 & $(-0.79 ;-0.04)$ & 0.66 & $(-0.42 ; 1.00)$ & -0.62 & $(-0.73 ;-0.46)$ & 0.28 & $(0.09 ; 0.46)$ \\
\hline \multicolumn{13}{|l|}{ Frontal lobe } \\
\hline Superior frontal gyrus & -0.79 & $(-0.83 ;-0.74)$ & 0.25 & $(0.14 ; 0.35)$ & -0.84 & $(-1.00 ; 1.00)$ & 0.22 & $(-1.00 ; 1.00)$ & -0.72 & $(-0.80 ;-0.60)$ & 0.19 & $(-0.01 ; 0.38)$ \\
\hline Rostral middle frontal gyrus & -0.57 & $(-0.64 ;-0.49)$ & 0.46 & $(0.38 ; 0.55)$ & -0.60 & $(-0.87 ;-0.03)$ & 0.57 & $(0.22 ; 0.97)$ & -0.51 & $(-0.65 ;-0.33)$ & 0.28 & $(0.07 ; 0.46)$ \\
\hline Caudal middle frontal gyrus & -0.66 & $(-0.72 ;-0.60)$ & 0.30 & $(0.20 ; 0.40)$ & -0.81 & $(-0.98 ;-0.33)$ & 0.52 & $(-0.03 ; 0.94)$ & -0.48 & $(-0.63 ;-0.31)$ & 0.11 & $(-0.10 ; 0.32)$ \\
\hline Lateral orbitofrontal cortex & -0.36 & $(-0.45 ;-0.26)$ & 0.73 & $(0.67 ; 0.78)$ & -0.42 & $(-0.94 ; 0.07)$ & 0.86 & $(0.48 ; 1.00)$ & -0.13 & $(-0.33 ; 0.08)$ & 0.61 & $(0.47 ; 0.72)$ \\
\hline Medial orbitofrontal cortex & -0.34 & $(-0.43 ;-0.24)$ & 0.80 & $(0.76 ; 0.84)$ & -0.53 & $(-1.00 ; 0.41)$ & 1.00 & $(0.52 ; 1.00)$ & -0.12 & $(-0.31 ; 0.08)$ & 0.76 & $(0.67 ; 0.83)$ \\
\hline Pars opercularis & -0.52 & $(-0.59 ;-0.44)$ & 0.31 & $(0.21 ; 0.40)$ & -0.70 & $(-1.00 ;-0.31)$ & 0.41 & $(-0.02 ; 0.79)$ & -0.40 & $(-0.57 ;-0.21)$ & 0.16 & $(-0.05 ; 0.36)$ \\
\hline Pars orbitalis & -0.45 & $(-0.53 ;-0.36)$ & 0.38 & $(0.29 ; 0.47)$ & -0.73 & $(-1.00 ; 0.82)$ & 0.50 & $(0.20 ; 0.90)$ & -0.24 & $(-0.42 ;-0.04)$ & 0.23 & $(0.02 ; 0.42)$ \\
\hline Pars triangularis & -0.53 & $(-0.60 ;-0.44)$ & 0.37 & $(0.28 ; 0.46)$ & -0.65 & $(-0.98 ;-0.36)$ & 0.54 & $(-1.00 ; 1.00)$ & -0.43 & $(-0.58 ;-0.24)$ & 0.24 & $(0.05 ; 0.41)$ \\
\hline Frontal pole & -0.33 & $(-0.42 ;-0.23)$ & 0.77 & $(0.72 ; 0.81)$ & -0.33 & $(-1.00 ; 1.00)$ & 0.87 & $(-1.00 ; 1.00)$ & -0.26 & $(-0.46 ;-0.04)$ & 0.70 & $(0.58 ; 0.78)$ \\
\hline Precentral gyrus & -0.74 & $(-0.79 ;-0.69)$ & 0.25 & $(0.15 ; 0.35)$ & -0.97 & $(-1.00 ;-0.64)$ & 0.11 & $(-0.97 ; 0.75)$ & -0.65 & $(-0.76 ;-0.52)$ & 0.19 & $(-0.01 ; 0.38)$ \\
\hline Paracentral lobule & -0.65 & $(-0.71 ;-0.58)$ & 0.04 & $(-0.06 ; 0.15)$ & -0.41 & $(-1.00 ; 1.00)$ & 0.07 & $(-1.00 ; 1.00)$ & -0.55 & $(-0.68 ;-0.39)$ & 0.10 & $(-0.10 ; 0.29)$ \\
\hline \multicolumn{13}{|l|}{ Cingulate cortex } \\
\hline $\begin{array}{l}\text { Rostral anterior cingulate } \\
\text { cortex }\end{array}$ & -0.27 & $(-0.37 ;-0.17)$ & 0.63 & $(0.56 ; 0.69)$ & -0.42 & $(-1.00 ; 1.00)$ & 0.57 & $(-1.00 ; 1.00)$ & -0.38 & $(-0.53 ;-0.20)$ & 0.62 & $(0.47 ; 0.73)$ \\
\hline $\begin{array}{l}\text { Caudal anterior cingulate } \\
\text { cortex }\end{array}$ & -0.30 & $(-0.40 ;-0.20)$ & 0.05 & $(-0.06 ; 0.15)$ & -0.68 & $(-1.00 ; 1.00)$ & -0.04 & $(-1.00 ; 1.00)$ & -0.21 & $(-0.42 ; 0.00)$ & 0.10 & $(-0.11 ; 0.31)$ \\
\hline Posterior cingulate cortex & -0.21 & $(-0.31 ;-0.10)$ & 0.21 & $(0.10 ; 0.31)$ & -0.58 & $(-1.00 ;-0.04)$ & 0.39 & $(-0.78 ; 0.98)$ & -0.10 & $(-0.31 ; 0.12)$ & 0.26 & $(0.06 ; 0.45)$ \\
\hline Isthmus cingulate cortex & -0.31 & $(-0.41 ;-0.21)$ & 0.64 & $(0.58 ; 0.70)$ & -0.34 & $(-1.00 ; 1.00)$ & 1.00 & $(-1.00 ; 1.00)$ & -0.33 & $(-0.51 ;-0.13)$ & 0.69 & $(0.58 ; 0.78)$ \\
\hline \multicolumn{13}{|l|}{ Parietal lobe } \\
\hline Superior parietal cortex & -0.69 & $(-0.75 ;-0.63)$ & 0.29 & $(0.19 ; 0.39)$ & -0.81 & $(-1.00 ; 0.42)$ & 0.50 & $(-0.06 ; 1.00)$ & -0.67 & $(-0.77 ;-0.53)$ & 0.07 & $(-0.14 ; 0.26)$ \\
\hline Inferior parietal cortex & -0.57 & $(-0.64 ;-0.49)$ & 0.35 & $(0.25 ; 0.45)$ & -0.64 & $(-0.98 ;-0.19)$ & 0.46 & $(-0.30 ; 0.98)$ & -0.43 & $(-0.59 ;-0.24)$ & 0.18 & $(-0.03 ; 0.38)$ \\
\hline Supramarginal gyrus & -0.62 & $(-0.68 ;-0.55)$ & 0.32 & $(0.22 ; 0.42)$ & -0.61 & $(-0.84 ;-0.11)$ & 0.45 & $(-0.11 ; 0.95)$ & -0.62 & $(-0.73 ;-0.47)$ & 0.07 & $(-0.13 ; 0.26)$ \\
\hline Precuneus & -0.64 & $(-0.70 ;-0.57)$ & 0.31 & $(0.21 ; 0.40)$ & -0.69 & $(-0.96 ;-0.43)$ & 0.72 & $(0.10 ; 1.00)$ & -0.50 & $(-0.65 ;-0.32)$ & 0.09 & $(-0.11 ; 0.29)$ \\
\hline Postcentral gyrus & -0.64 & $(-0.70 ;-0.57)$ & 0.19 & $(0.09 ; 0.29)$ & -0.77 & $(-1.00 ; 0.08)$ & 0.95 & $(-1.00 ; 1.00)$ & -0.53 & $(-0.66 ;-0.37)$ & -0.05 & $(-0.24 ; 0.14)$ \\
\hline \multicolumn{13}{|l|}{ Occipital lobe } \\
\hline Lingual gyrus & -0.51 & $(-0.58 ;-0.42)$ & 0.44 & $(0.35 ; 0.52)$ & -0.74 & $(-0.99 ;-0.40)$ & 0.69 & $(-0.30 ; 1.00)$ & -0.45 & $(-0.61 ;-0.27)$ & 0.35 & $(0.18 ; 0.51)$ \\
\hline Pericalcarine cortex & -0.12 & $(-0.22 ;-0.01)$ & 0.32 & $(0.22 ; 0.41)$ & -0.19 & $(-0.77 ; 0.36)$ & 0.57 & $(-0.13 ; 1.00)$ & -0.04 & $(-0.27 ; 0.19)$ & 0.24 & $(0.04 ; 0.43)$ \\
\hline Cuneus & -0.28 & $(-0.38 ;-0.17)$ & 0.30 & $(0.20 ; 0.40)$ & -0.30 & $(-0.69 ; 0.31)$ & 0.54 & $(0.11 ; 1.00)$ & -0.26 & $(-0.45 ;-0.04)$ & 0.17 & $(-0.05 ; 0.38)$ \\
\hline Lateral occipital cortex & -0.50 & $(-0.58 ;-0.41)$ & 0.58 & $(0.50 ; 0.65)$ & -0.50 & $(-0.77 ;-0.18)$ & 0.80 & $(-1.00 ; 1.00)$ & -0.59 & $(-0.72 ;-0.41)$ & 0.56 & $(0.38 ; 0.69)$ \\
\hline \multicolumn{13}{|l|}{ Temporal lobe } \\
\hline Superior temporal gyrus & -0.64 & $(-0.70 ;-0.57)$ & 0.20 & $(0.09 ; 0.30)$ & -0.60 & $(-1.00 ; 0.72)$ & 0.53 & $(-0.12 ; 1.00)$ & -0.56 & $(-0.68 ;-0.40)$ & -0.09 & $(-0.28 ; 0.12)$ \\
\hline Middle temporal gyrus & -0.40 & $(-0.49 ;-0.30)$ & 0.47 & $(0.39 ; 0.56)$ & -0.48 & $(-0.86 ; 0.03)$ & 0.58 & $(0.18 ; 0.91)$ & -0.32 & $(-0.50 ;-0.12)$ & 0.36 & $(0.16 ; 0.53)$ \\
\hline Inferior temporal gyrus & -0.24 & $(-0.34 ;-0.13)$ & 0.73 & $(0.68 ; 0.78)$ & -0.62 & $(-1.00 ; 1.00)$ & 0.72 & $(-0.59 ; 0.92)$ & -0.21 & $(-0.41 ;-0.01)$ & 0.77 & $(0.66 ; 0.85)$ \\
\hline Transverse temporal cortex & -0.56 & $(-0.63 ;-0.48)$ & 0.16 & $(0.05 ; 0.26)$ & -0.59 & $(-0.76 ;-0.40)$ & 0.33 & $(-0.12 ; 1.00)$ & -0.52 & $(-0.67 ;-0.34)$ & -0.07 & $(-0.27 ; 0.14)$ \\
\hline $\begin{array}{l}\text { Banks of the sup. temp. } \\
\text { sulcus }\end{array}$ & -0.42 & $(-0.51 ;-0.33)$ & 0.39 & $(0.29 ; 0.48)$ & -0.86 & $(-1.00 ;-0.32)$ & 0.36 & $(-0.31 ; 0.64)$ & -0.11 & $(-0.31 ; 0.09)$ & 0.40 & $(0.21 ; 0.57)$ \\
\hline Entorhinal cortex & -0.12 & $(-0.23 ;-0.01)$ & 0.61 & $(0.53 ; 0.67)$ & -0.99 & $(-1.00 ; 1.00)$ & 0.75 & $(0.44 ; 0.95)$ & 0.01 & $(-0.21 ; 0.22)$ & 0.43 & $(0.21 ; 0.61)$ \\
\hline
\end{tabular}




\begin{tabular}{llllllllllllll} 
Parahippocampal cortex & -0.42 & $(-0.51 ;-0.33)$ & 0.49 & $(0.41 ; 0.57)$ & -0.20 & $(-1.00 ; 1.00)$ & 1.00 & $(-1.00 ; 1.00)$ & -0.37 & $(-0.52 ;-0.18)$ & 0.43 & $(0.25 ; 0.58)$ \\
Fusiform gyrus & -0.45 & $(-0.53 ;-0.36)$ & 0.56 & $(0.48 ; 0.63)$ & -0.81 & $(-1.00 ; 1.00)$ & 0.06 & $(-1.00 ; 1.00)$ & -0.25 & $(-0.44 ;-0.06)$ & 0.65 & $(0.52 ; 0.74)$ \\
Temporal pole & -0.04 & $(-0.14 ; 0.07)$ & 0.78 & $(0.74 ; 0.82)$ & -0.08 & $(-1.00 ; 1.00)$ & 0.85 & $(-1.00 ; 1.00)$ & -0.07 & $(-0.28 ; 0.14)$ & 0.69 & $(0.56 ; 0.79)$ \\
\hline
\end{tabular}

$r_{p}=$ phenotypic correlation; $r_{g}=$ genetic correlation; $r_{e}=$ unique environment correlation; $C M D=$ cortical mean diffusivity; CT = cortical thickness; $W M M D=W M$ mean diffusivity; $95 \% \mathrm{Cl}=$ corrected $95 \%$ confidence intervals. Common environment correlations and correlations between cortical thickness and white matter mean diffusivity are not show. 
Figure 1. Significant heritability estimates $\left(a^{2}\right)$ from ACE model of cortical mean diffusivity.
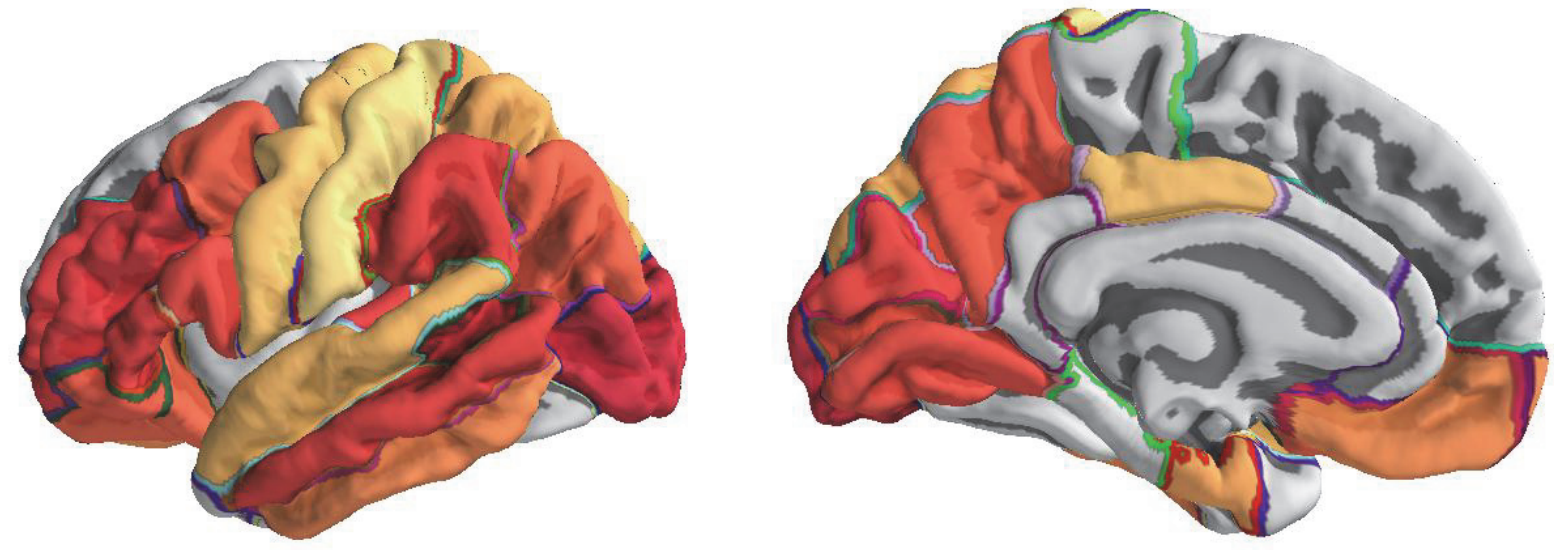

Figure 2. Significant genetic correlations $\left(r_{g}\right)$ between cortical mean diffusivity and cortical thickness.
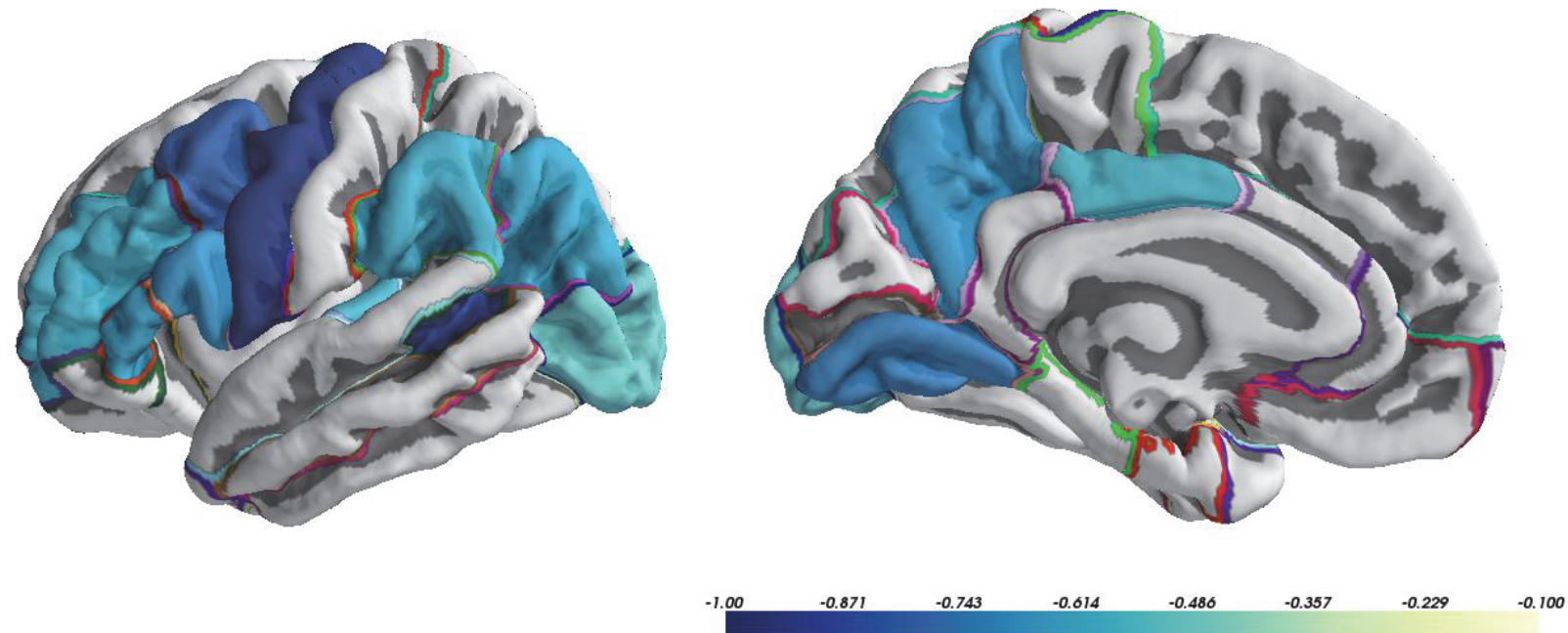
Figure 3. Significant genetic correlations $\left(r_{g}\right)$ between cortical mean diffusivity and white matter mean diffusivity.
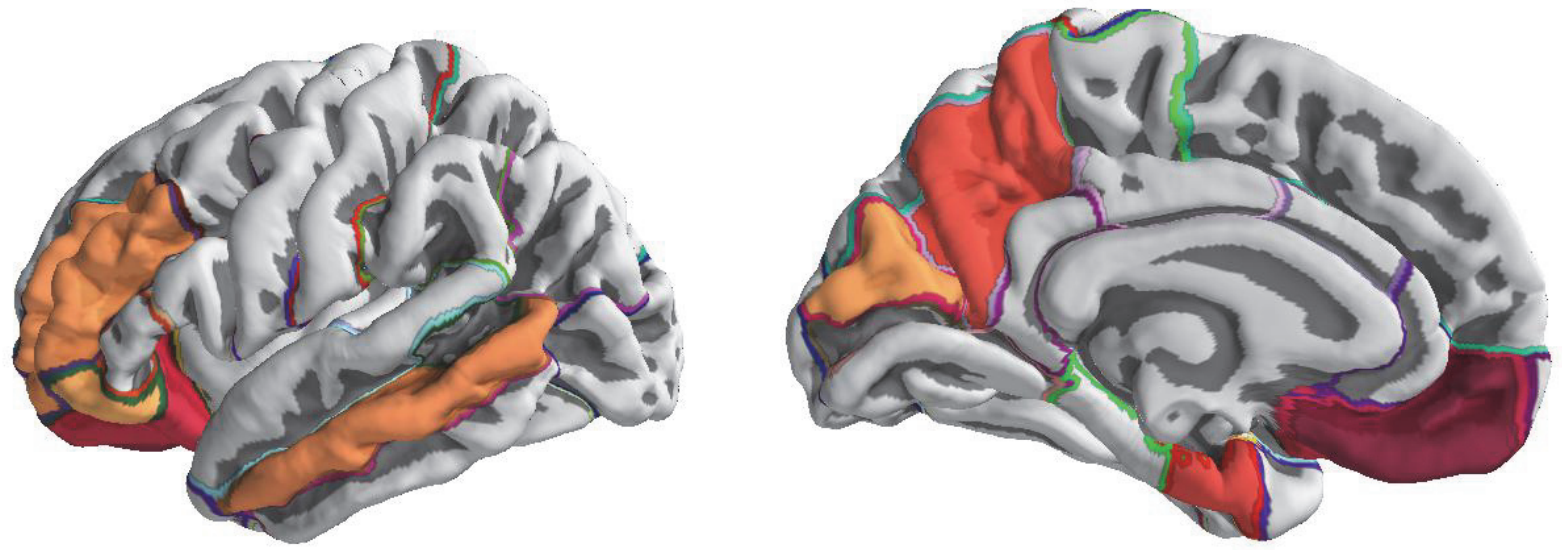

0.100 0.357 0.743 